\title{
Genetic association between test-day milk fat to protein ratio and fertility traits in dairy cows: A random regression model analyses
}

\author{
E. Negussie, I. Strandén, E. A. Mäntysaari \\ MTT Agrifood Research, Biotechnology and Food Research, Biometrical Genetics, 31600 Jokioinen, \\ Finland
}

\begin{abstract}
In early lactating cows changes in energy balance (EB) and subsequent mobilisation of body reserves result changes in milk yield (MY) and milk composition. These variations could be used as indicators of changes or problems in feeding, health and fertility. Recently it is postulated that changes in milk fat to protein ratio (FPR) may be associated with a negative EB. A negative EB, typical of the early phase of lactation impairs cows fertility whereas a recovery in EB from its most negative state, signals the initiation of ovarian activity indicating a direct relationship. Therefore, since measuring EB in large populations is difficult and expensive, assessing the genetic association between ratios of milk components and fertility traits, especially at different stages of lactation may provide an inexpensive indicator of EB. Besides, in selection programs, such information could be used to identify sires and cow families that have chronic energy deficiency and poor fertility in early lactation. The objectives of this study were to estimate covariance components for testday FPR, MY and fertility traits and to assess the genetic associations between these traits during lactation using random regression models (RRM). Genetic parameters of test-day FPR, MY and fertility were estimated using bivariate RRM that combine traits with different data structures employing a meta-model analyses. Fertility traits considered were days from calving to insemination (DFI), days open (DO), number of inseminations (NI), non-return rate to 56 days (NRR). Data was from a total of 22422 first lactation Finnish Ayrshire cows. The sire pedigree file had 638 males of which 509 sires had daughters with data. Heritability of test-day FPR during lactation ranged from 0.08 to 0.17 while the heritability of DFI, DO, NI and NRR were $0.06,0.03,0.01$ and 0.02 , respectively. Genetic correlations between test-day FPR and MY during early lactation ranged from $0.10-0.28$. The positive genetic correlation between these traits indicates that genetically high producing cows tend to have high FPR during early lactation. Genetic correlations between test-day FPR and DFI, DO, NI, and NRR during early lactation were from 0.05-0.28, 0.03-0.24, $0.01-0.03$, and $-0.01-0.03$, respectively. Of the fertility traits, the strongest genetic association was between test-day FPR and DFI or DO. The relatively low correlations between test-day FPR and the other fertility traits (NI and NRR) could be due to they are measures of fertility that are recorded after cows recovered from the most negative state of EB and started cycling. The positive and relatively higher genetic correlations between test-day FPR and DFI or DO indicate cows with high test-day FPR in early lactation tends to take longer from calving to first insemination and successful conception. The results from this study indicate that high FPR in early lactation could be used as an indicator of negative EB and cows of poor fertility, which take longer time from calving to first insemination and successful conception.
\end{abstract}

Key words:

Fertility, milk fat to protein ratio, energy balance, genetic correlation, random regression model 


\section{Introduction}

Genetic improvement in dairy cows has markedly increased milk yield (MY). However, increased production has been associated with reduced fertility in dairy cows (Pösö and Mantysaari 1996; Pryce et al. 1998; Pryce and Veerkamp, 2001; Roxström et al. 2001). In high producing cows, increasing dietary intake fails to keep pace with rising milk production during early lactation. This result in a negative energy balance (EB) and to overcome the energy deficit body reserves are mobilised leading to some body weight loss. As a consequence marked changes in milk yield and milk component ratios are typical of this phase of lactation. Therefore, dairy breeding programs that are focused on improving production are likely to lead to cows that are in more negative EB and utilise body reserves, which may be at the expense of other body functions such as fertility.

Energy balance is difficult to measure in large populations. Therefore there is interest in other traits, which could be indicators of EB (Coffey et al., 2001) and may subsequently be related to the health and fertility status of an animal. Body condition score is one of these measures (de Vries and Veerkamp, 2000; Veerkamp et al., 2001). It is widely used in many species to assess body composition and energy status of animals. However, BCS is a subjective measure and routine recording of BCS is not a common practice on most dairy farms (de Vries and Veerkamp, 2000).

Several studies have indicated that in early lactation milk composition changes are related to health, fertility and other physiological effects associated with energy balance (Von Farries, 1983; Grieve et al., 1986; Butler and Smith, 1989; Loeffler et al., 1999). In this regard, Kaufmann (1979) illustrated a positive association between milk protein \% in early lactation and fertility of cows, which may be attributed to the relationship of milk protein to energy supply. Reid (1983) reported reduced reproductive performance in cows with fatty liver after calving, a part of the generalised fat mobilization syndrome that occurs in response to energy deficit in early lactation. Some results also suggest that the milk fat to protein ratio (FPR) is negatively related to EB (Grieve et al., 1986). Loeffler et al., (1999) indicated that a change in fat to protein ratio and the milk fat percentage during early lactation had a negative effect on conception at first insemination. It is therefore, hypothesised that changes in milk composition and ratios of milk components could help monitor the EB status of cows in early lactation.

In contrast to BCS, milk yield and milk composition data are available in almost all milk-recorded herds. Thus, the use of such data to identify between cow variations in EB might be an inexpensive alternative to measuring feed intake or BCS. One way of validating the hypothesis whether ratios of milk components can be used as indicators of EB is to assess the genetic association between component ratios and fertility traits during the different stages of lactation. A clear understanding of this relationship in dairy cows would enable the development of a low cost indicator of EB. Furthermore, in selection schemes, such information could be utilised to identify sires and cow families that experience severe energy deficiency and poor fertility in early lactation. The objectives of this study were a) to estimate covariance components for test-day FPR, MY and cow fertility traits and b) to assess the genetic associations between test-day FPR and cow fertility traits during the different stages of lactation using random regression models (RRM).

\section{Material and methods}

\subsection{Data and trait definition}

Data for this study were provided by the Faba Breeding. The data included information on test-day milk, protein and fat yield, and fertility traits of first-lactation Finnish Ayrshire cows. The test-day milk fat to protein ratio was calculated for each test-day.

Fertility traits were the number of inseminations (NI) in service period; days from calving to first insemination (DFI), non-return rate (NRR) to 56 days after first insemination and days open (DO) as the number of days from calving to successful conception. A test-day record comprised observations on test-day FPR and MY recorded within 8 to 365 days in milk. The data included a total of 22,422 cows. Details of the data are given in Table 1. The sire pedigree file had 686 males of which 509 had daughters with data. 
Table 1 . Summary statistics of the data

\begin{tabular}{lrr}
\hline Traits & No. observations & Mean (SD) \\
\hline DFI & 16859 & $84.1(27)$ \\
DO & 16859 & $124.7(62)$ \\
NI & 16859 & $1.98(1.19)$ \\
NRR56 & 16859 & $0.55(0.49)$ \\
Milk yield & 77945 & $21.3(4.89)$ \\
Protein yield & 77945 & $0.72(0.14)$ \\
Fat yield & 77945 & $0.92(0.21)$ \\
FPR & 77945 & $1.29(0.21)$ \\
\hline
\end{tabular}

\subsection{Data Analysis}

\subsubsection{Model}

Initially, univariate analyses of test-day FPR and MY were made to determine the appropriate order of polynomials for random regressions. This was followed by bivariate analyses. In the bivariate analyses of fertility traits with test-day FPR and MY, the sire additive genetic and permanent environmental effects for the test-day traits were modeled by second-order orthogonal Legendre polynomials. Whilst for fertility traits DFI, DO, NI and NRR, only the intercept term was fitted. The modelling of fixed effects was the same for all traits with the exception of the lactation curve, which was modeled only for the test-day traits.

For instance, the description of the bivariate RRM for test-day FPR and a fertility trait was:

$$
\begin{aligned}
{\left[\begin{array}{l}
\mathrm{y}_{\text {FPR }} \\
\mathrm{y}_{\text {FERT }}
\end{array}\right] } & =\left[\begin{array}{l}
\mathrm{f}_{\mathrm{FPR}_{\mathrm{i}}} \\
\mathrm{f}_{\mathrm{FERT}_{\mathrm{i}}}
\end{array}\right]+\left[\begin{array}{l}
\mathrm{ym}_{\mathrm{FPR}_{\mathrm{k}}} \\
\mathrm{ym}_{\mathrm{FERT}_{\mathrm{k}}}
\end{array}\right]+\left[\begin{array}{l}
\mathrm{hy}_{\mathrm{FPR}_{\mathrm{h}}} \\
\mathrm{hy}_{\mathrm{FERT}_{\mathrm{h}}}
\end{array}\right]+\left[\begin{array}{l}
\left.\Sigma_{\mathrm{r}=0}^{4} \phi_{\pi}(\mathrm{d})_{\mathrm{r}} \mathrm{b}_{\mathrm{FPR}_{1}}\right]+\left[\begin{array}{l}
\mathrm{htd} \\
0
\end{array}\right] \\
0
\end{array}\right]+\left[\begin{array}{l}
\Sigma_{\mathrm{r}=0}^{2} \phi_{\alpha}(\mathrm{d})_{\mathrm{r}} \mathrm{p}_{\mathrm{FPR}_{\mathrm{m}}} \\
\mathrm{p}_{\mathrm{FERT}_{\mathrm{m}}}
\end{array}\right]+\left[\begin{array}{l}
\Sigma_{\mathrm{r}=0}^{2} \phi_{\alpha}(\mathrm{d})_{\mathrm{r}} \mathrm{a}_{\mathrm{FPR}_{\mathrm{n}}} \\
\mathrm{a}_{\mathrm{FERT}_{\mathrm{n}}}
\end{array}\right]+\left[\begin{array}{l}
\mathrm{e}_{\mathrm{FPR}} \\
\mathrm{e}_{\mathrm{FERT}}
\end{array}\right]
\end{aligned}
$$

where $\mathrm{y}_{\mathrm{FPR}}$ and $\mathrm{y}_{\mathrm{FERT}}$ are test-day FPR observations, and observations (lactationwise) on fertility, respectively, recorded in herd test-day $o$, in year $\times$ month of calving $k$, herd-year $h$, on a cow $m$ belonging to the calving age class $i$, calving-year $\times$ calving-season class $l$ and measured on DIM $d$.

The covariables for coefficients $b_{. r}(r=0, \ldots, 4)$ were:

$$
\phi_{\pi}(d)=\left[\begin{array}{llll}
\mathrm{c}_{0} & \mathrm{c}_{1} & \mathrm{c}_{2} & \mathrm{c}_{3} \\
\exp (w \mathrm{~d})
\end{array}\right]^{\mathrm{T}}
$$

where $\mathrm{c}_{0} \mathrm{c}_{1} \mathrm{c}_{2} \mathrm{c}_{3}$ represent coefficients of the third-order orthogonal Legendre polynomial at DIM $d$ and $w$ is coefficient of the exponential term of the Wilmink function (Wilmink, 1987). The most appropriate coefficients of the exponential term $(w)$ that fitted the current data for modelling the fixed lactation curves were estimated to be -0.05 for MY (Lidauer et al., 2003).

The covariance structure for models with random $h t d$ effect was defined as:

$\operatorname{Var}\left[\begin{array}{l}\mathbf{h t d} \\ \mathbf{a} \\ \mathbf{p} \\ \mathbf{e}\end{array}\right]=\left[\begin{array}{cccc}\mathbf{H} & 0 & 0 & 0 \\ 0 & \mathbf{G} \otimes \mathbf{A} & 0 & 0 \\ 0 & 0 & \mathbf{P} \otimes \mathbf{I} & 0 \\ 0 & 0 & 0 & \mathbf{R}\end{array}\right]$

where $\mathbf{H}$ is a diagonal matrix of the form $\mathbf{I} \sigma_{h}^{2}$, and $\sigma_{h}^{2}$ is the variance of the random htd effect, $\mathbf{A}$ is the matrix of additive genetic relationships among sires, $\otimes$ is the Kronecker product, $\mathbf{G}$ and $\mathbf{P}$ are covariance matrices of the random regression coefficients for sire additive genetic and cow permanent environmental effects, $\mathbf{R}$ is the diagonal matrix of the form $\mathbf{I} \sigma_{e}^{2}$, and $\sigma_{e}^{2}$ is residual variance. 
Fixed effects were age at calving (f), year $\times$ month of calving (ym), herd $\times$ year (hy) and regression coefficients (b) describing the shape of the lactation curve within calving-year $\times$ calving-season classes. The calving seasons were October to February, March to June and July to September. The herd sizes are small in Finland and therefore the herd effect was modeled by fixed herd-year and random herd test-day (htd) components. For fertility traits, a random herd-year and no htd effect was fitted.

Random genetic effects were $\mathrm{a}_{\mathrm{FPR}}$ and $\mathrm{a}_{\mathrm{FERT}}$. The $\mathrm{a}_{\mathrm{FPR}}$ was random genetic effects for test-day FPR with:

$$
\phi_{\alpha}(d)=\left[\begin{array}{lll}
\mathrm{c}_{0} & \mathrm{c}_{1} & \mathrm{c}_{2}
\end{array}\right]^{\mathrm{T}}
$$

representing a second-order orthogonal Legendre polynomial at DIM $d$. Random effects $\mathrm{p}_{\mathrm{FPR}}$ and $\mathrm{p}_{\mathrm{FERT}}$ were non-genetic animal effects for a cow $m$ with $\phi_{\alpha}(d)$ as in (2) for test-day FPR, and fertility traits, respectively. Random $\mathrm{e}_{\mathrm{FPR}}$ and $\mathrm{e}_{\mathrm{FERT}}$ were measurement errors.

In order to facilitate accurate estimates of parameters for the fertility traits, the bivariate RRM has to be defined as both test-day and fertility traits would be repeated observations but never recorded simultaneously. Thus the variance between daily residuals was assumed uncorrelated, but the animalwise environmental covariance among traits was modeled by permanent environmental effect. The estimation of this component for fertility traits was accomplished during REML analyses by restricting the residual variance of fertility traits to a predetermined operationally small value. As a result, most of the residual variance entered into the permanent environmental component facilitating the estimation of permanent environmental correlation between fertility and test-day FPR. The resulting covariance components of the random regression coefficients for sire additive genetic and cow permanent environmental effects were then used to derive the day to day heritabilities and correlations. All analyses were made using the DMU package (Madsen and Jensen, 2000).

\subsubsection{Estimation of heritabilities and correlations}

Daily sire variance of test-day FPR at time $d_{\mathrm{i}}$ can be written as:

$$
\sigma_{s}^{2}\left(d_{i}\right)=\phi_{\alpha}^{\prime}\left(d_{i}\right) \mathbf{G} \phi_{\alpha}\left(d_{i}\right) \text {, }
$$

where $\mathbf{G}$ is covariance matrix of the random sire regression coefficients for test-day FPR. Heritability of a trait at any time $d_{\mathrm{i}}$ along the lactation trajectory was estimated as:

$\hat{h}_{d_{i}}^{2}=4 \hat{\sigma}_{s}^{2}\left(d_{i}\right) /\left[\hat{\sigma}_{e}^{2}+\hat{\sigma}_{p}^{2}\left(d_{i}\right)+\hat{\sigma}_{s}^{2}\left(d_{i}\right)+\hat{\sigma}_{h t d}^{2}\right\rfloor$

where $\hat{\sigma}_{p}^{2}$ is the variance of permanent environmental effects given as $\left(\phi^{\prime}\left(d_{i}\right) \mathbf{P} \phi\left(d_{i}\right)\right)$. Genetic correlation between a test-day FPR and fertility trait at times $d_{\mathrm{i}}$ was estimated as:

$$
\left.\hat{r}_{g}\left(d_{i}\right)=\left(\phi_{\alpha}^{\prime}\left(d_{i}\right) \mathbf{G}_{F P R, F E R T} \mathbf{1}\right) / \hat{\sigma}_{F P R}^{2}\left(d_{i}\right) \hat{\sigma}_{F E R T}^{2}\right]^{1 / 2} \text {. where } \mathbf{G}_{\mathrm{FPR}, \mathrm{FERT}} \text { is random regression coefficients }
$$

of the genetic sire covariance between the test-day FPR and fertility trait, and $\hat{\sigma}_{F E R T}^{2}$ is the sire variance of the fertility trait.

\section{Results and discussion}

\subsection{Mean and standard deviation of FPR}

The overall average (SD) of test-day FPR during first lactation was $1.3(0.21)$ (Figure 1). In early lactation (from $\mathrm{d} 8$ to 60 ) the average test-day FPR ranged from 1.3 to 1.4. This was followed by a slight decline in mid lactation (from d 60 to 150) ranging from 1.2 to 1.25 . From d 150 to $\mathrm{d} 200$ the test-day FPR was relatively constant and started to increase towards the end of the lactation. Working with Holstein cows 
Čejna and Chládek (2005) indicated that the optimum FPR is between 1.2 and 1.4. They said lower values are likely to lead to subclinical rumen acidosis, which can endanger reproductive performance of cows and enhance a possible development of mineral metabolism disorders. On the other hand, a FPR higher than 1.4 signals energy deficiency and subclinical ketosis if ketone bodies are present. In this study, they found that the FPR changes during lactation and revealed higher values of this ratio are at the beginning of lactation in the observed herd. They concluded that monitoring of the FPR is relevant for correcting and adjusting possible nutritional deficiencies in cows. Similarly, Heuer et al. (1999) indicated that cows with FPR $>1.5$ had higher risks of ketosis, displaced abomasums, ovarian cyst, lameness, and mastitis. They also indicated that those cows produced more milk but had poor reproductive performance indicating a close associations between FPR, energy balance and cow fertility.

\subsection{Estimates of genetic parameters for test-day milk fat to protein ratio}

The heritability of test-day FPR during first lactation ranged from 0.08 to 0.17 (Table 2). In early lactation (from $\mathrm{d} 8$ to 60 ) the heritability of FPR ranged from 0.08 to 0.11 . Starting from d 60, the heritability of testday FPR increased gradually and reached peak towards the end of lactation. The wide ranges of the heritability estimates indicate that there is a sizeable genetic variation in test-day FPR during first lactation. One of the reasons for the slightly lower heritability during the early lactation could be the high non-genetic environmental variation during this period. Genetic correlations between different days in milk for test-day FPR were 0.97 between DIM 30 and 60 whilst 0.65 between DIM 30 and 305. This indicates that correlations between adjacent test-days were higher than between distant test-days implying that they may be affected by the same set of genes.

\subsection{Genetic and phenotypic associations between test-day FPR and milk yield}

Genetic and phenotypic correlations between test-day FPR and MY for selected days in milk are in Table 2. Genetic correlations between test-day FPR and MY in early lactation (from DIM 8 to 60) ranged from 0.01 to 0.13 . After DIM 60, however, correlations ranged from -0.11 to -0.22 . The positive genetic correlations between the two traits in early lactation indicate that cows with high milk production are also cows with high FPR and has the propensity to mobilize body reserves to meet the high energy demands of peak production. After the peak milk production period, however, the genetic correlation between the traits becomes negative. This may be an indication that cows have come out of the negative state of energy balance.. The phenotypic correlations between test-day FPR and MY was very low ranging from 0.01 to 0.02 in early lactation and were negative in late lactation (Table 2).

\subsection{Genetic and phenotypic correlations between test-day FPR and fertility traits.}

In early lactation (from DIM 8 to 60), the genetic correlation between test-day FPR and fertility traits ranged from 0.14 to 0.28 (Table 3). After DIM 60, however, the genetic correlation decreased and was negative towards the end of the lactation. The moderate positive genetic correlations in early lactation between the two traits indicate that high FPR (an indication of negative energy balance) is genetically correlated with poor fertility (i.e., longer days from calving to insemination, DFI). This association in early lactation was followed by very low correlations suggesting that by mid lactation cows are out of the negative state of EB.

Similarly, genetic associations between test-day FPR and DO during early lactation were positive and moderate. It ranged from 0.19 to 0.24 whilst correlations from d 60 to 305 were relatively lower and ranged from 0.03 to 0.13 (Table 3 ). The phenotypic correlations both in early and late lactations were low and close to zero. The positive and slightly higher genetic correlations between the two traits indicate that cows genetically with high FPR in early lactation are cows with poor fertility taking longer days from calving to successful conception.

The genetic and phenotypic correlations between test-day FPR and NI and between test-day FPR and NRR are in Table 3. Genetic correlations between test-day FPR and NI were positive and very low in early lactation. After d 60 to 305, the genetic correlations were negative and increased from -0.01 to -0.21 . The phenotypic correlations between these traits were also very low during lactation and ranged from -0.04 to 0.04. Rather similar results were observed for NRR (Table 3). 
In general, results from the present study show that there are two different groups of fertility traits and the strength of genetic associations between these traits and test-day FPR was different. The first group was interval traits and it included DFI and DO whilst the second group is success traits that included NI and NRR56, which are primarily, measure success of conception. Our results show strong genetic correlations in early lactation between test-day FPR and the interval fertility traits. This is to be expected because EB affects the length of the time from calving to the start of the ovarian or luteal activity and DFI and DO as fertility traits measures the interval from calving to insemination and conception. Hence close genetic associations between these fertility measures and FPR imply that high FPR in early lactation may indicate a negative EB and poor fertility.

On the other hand, the very low genetic and phenotypic associations between test-day FPR and success traits may be due to the fact that NI or NRR as fertility traits measure only the success of conception. They are recorded only after the cow comes out of the negative state of EB, gained condition and started cycling. But negative EB and marked changes in the ratios of the milk components happen mainly during early stages of lactation when the cow was mobilising body reserves. Thus, the low genetic and phenotypic associations between success fertility traits and test-day FPR during early lactation are justified.

\section{Conclusions}

The analysis of genetic associations between test-day FPR and MY showed that milk production in early lactation is positively correlated with test-day FPR suggesting that cows genetically high producers tend to have high FPR during this time. Among the fertility traits, only DFI and DO were strongly correlated with test-day FPR. The genetic and phenotypic correlations with the other fertility traits NI and NRR were very low. In summary, the result from this study indicates that genetically high milk producers have high FPR in early lactation and tend to take longer from calving to first insemination and successful conception. Thus, test-day FPR can be used as indicator of cows fertility and indirect measure of EB in early lactation.

\section{Acknowledgement}

The authors thank Faba Breeding for providing the data. This study was funded by the Finnish Ministry of Agriculture and Forestry, Faba Breeding, Breeding Center FABA, and Finnish Dairies Association.

\section{References}

Coffey, M. P., Emmans, G. C. \& Brotherstone, S. 2001. Genetic evaluations of dairy bulls for energy balancetraits using random regression. J. Dairy Sci. 85:2669-2678.

Čejna, V., \& Chládek, G. 2005. The importance of monitoring changes in milk fat to protein ratio in Holstein cows during lactation. J. Central European Agriculture 6:539-545.

De Vries, M. J. \& Veerkamp, R. F. 2000. Energy balance of dairy cattle in relation to milk production variables and fertility. J. Dairy Sci. 83:62-69.

Grieve, D. G., Korver, S., Rijpkema, Y. S., \& Hof, G. 1986. Relationship between milk composition and some nutritional parameters in early lactation. Livest. Prod. Sci. 14:239-254.

Kaufmann, W. 1979. Protein utilisation. In: W. H. Broster and H. Swan (Editors), Feeding Strategy for the High Yielding Dairy Cow. Granada, London, pp. 90-113.

Lidauer M., E. A. Mäntysaari, and I Stranden. 2003. Comparison of test-day models for genetic evaluation of production traits in dairy cattle. Livest. Prod. Sci. 79:73-86.

Loeffler, S. H., de Vries, M. J. \& Schukken, Y. H. 1999. The effects of time of disease occurrence, milk yield, and body condition on fertility of dairy cows. J. Dairy Sci. 82:2589-2604.

Pryce, J.E., R. J. Esslemont, R. Thompson, R. F. Veerkamp, M. A. Kossaibati, and G. Simm. 1998. Estimation of genetic parameters using health, fertility and production data from a management recording system for dairy cattle. Anim. Sci. 66:577-584.

Pryce, J.E. and R. F. Veerkamp. 2001. The incorporation of fertility indices in genetic improvement programs. Pages 223-236 in Fertility in the High Producing Dairy Cow. M. G. Diskin, ed. Br. Soc. Anim. Sci. Occ. Publ. No. 26. Edinburgh, Scotland.

Pösö, J., \& Mäntysaari, E. A. 1996. Genetic relationships between reproductive disorders, operational days open and milk yield. Livest. Prod. Sci. 46:41-48.

Reid, I. M. 1983. Reproductive performance and fatty liver in Guernsey cows. Anim. Reprod. Sci. 5:275-279.

Roxström, A., E. Strandberg, B. Berglund, U. Emanuelson, and J. Philipsson. 2001. Genetic and environmental correlations among the female fertility traits and between the ability to show oestrus and milk production in dairy cattle. Acta Agric. Scand., Sect. A. Anim. Sci. 51:192-199. 
Veerkamp. R. F., Koenen, E. P. C. \& De Jong, G. 2001. Genetic correlations among body condition score, yield and fertiltiy in first parity cows estimated by random regression models. J. Dairy Sci. 84:2327-2335.

Von Farries, E. 1983. Stoffwechselstorungen und ihr Einfluss auf die Zusammensetzung der milch. Zuchtungskunde. 55:265-274.

Wilmink, J.B.M. 1987. Adjustment of test-day milk, fat, and protein yields for age, season, and stage lactation. Livest. Prod. Sci. 16:335-348.

Table 2. Heritability (on diagonal) genetic (above diagonal) and phenotypic (below diagonal) associations between testday FPR and milk yield for selected DIMs from random regression model fitting second-order Legendre polynomials.

\begin{tabular}{cllllllllllllllll}
\hline Traits & \multicolumn{1}{c}{ MY } & \multicolumn{1}{c}{ FPR } \\
\hline \multirow{6}{*}{ MY } & DIM & 30 & 60 & 110 & 160 & 210 & 260 & 310 & 30 & 60 & 110 & 160 & 210 & 260 & 310 \\
& & & & & & & & & & & & & & & \\
& 30 & $\mathbf{0 . 1 3}$ & 0.98 & 0.93 & 0.87 & 0.80 & 0.70 & 0.58 & 0.13 & 0.06 & -0.02 & -0.07 & -0.12 & -0.15 & -0.17 \\
& 60 & 0.69 & $\mathbf{0 . 1 4}$ & 0.98 & 0.94 & 0.88 & 0.78 & 0.63 & 0.08 & 0.01 & -0.07 & -0.13 & -0.17 & -0.20 & -0.21 \\
& 110 & 0.61 & 0.68 & $\mathbf{0 . 1 5}$ & 0.99 & 0.95 & 0.86 & 0.70 & 0.02 & -0.05 & -0.12 & -0.17 & -0.22 & -0.24 & -0.25 \\
& 160 & 0.53 & 0.63 & 0.71 & $\mathbf{0 . 1 6}$ & 0.98 & 0.91 & 0.77 & -0.01 & -0.08 & -0.15 & -0.19 & -0.23 & -0.25 & -0.25 \\
& 210 & 0.45 & 0.56 & 0.66 & 0.71 & $\mathbf{0 . 1 8}$ & 0.97 & 0.87 & -0.03 & -0.09 & -0.15 & -0.19 & -0.22 & -0.24 & -0.24 \\
& 260 & 0.38 & 0.46 & 0.55 & 0.62 & 0.71 & $\mathbf{0 . 1 9}$ & 0.96 & -0.02 & -0.07 & -0.12 & -0.15 & -0.18 & -0.19 & -0.18 \\
& 310 & 0.28 & 0.31 & 0.37 & 0.44 & 0.57 & 0.73 & $\mathbf{0 . 2 0}$ & 0.01 & -0.03 & -0.07 & -0.09 & -0.11 & -0.11 & -0.11 \\
& & & & & & & & & & & & & & & \\
& 30 & 0.02 & 0.02 & 0.03 & 0.03 & 0.04 & 0.05 & 0.05 & $\mathbf{0 . 0 8}$ & 0.97 & 0.89 & 0.82 & 0.75 & 0.71 & 0.66 \\
& 60 & 0.01 & 0.01 & 0.01 & 0.01 & 0.02 & 0.03 & 0.04 & 0.47 & $\mathbf{0 . 1 0}$ & 0.97 & 0.93 & 0.87 & 0.83 & 0.75 \\
& 110 & -0.01 & -0.02 & -0.02 & -0.02 & -0.02 & 0.01 & 0.01 & 0.35 & 0.37 & $\mathbf{0 . 1 3}$ & 0.99 & 0.96 & 0.91 & 0.82 \\
FPR & 160 & -0.03 & -0.04 & -0.05 & -0.05 & -0.05 & -0.03 & -0.01 & 0.25 & 0.30 & 0.35 & $\mathbf{0 . 1 5}$ & 0.99 & 0.96 & 0.86 \\
& 210 & -0.04 & -0.06 & -0.07 & -0.07 & -0.07 & -0.06 & -0.03 & 0.16 & 0.23 & 0.31 & 0.36 & $\mathbf{0 . 1 6}$ & 0.99 & 0.91 \\
& 260 & -0.05 & -0.07 & -0.08 & -0.08 & -0.08 & -0.07 & -0.05 & 0.13 & 0.20 & 0.28 & 0.33 & 0.36 & $\mathbf{0 . 1 6}$ & 0.97 \\
& 310 & -0.06 & -0.07 & -0.08 & -0.09 & -0.09 & -0.08 & -0.06 & 0.15 & 0.20 & 0.25 & 0.28 & 0.31 & 0.33 & $\mathbf{0 . 1 7}$ \\
\hline
\end{tabular}

Table 3. Heritability (diagonal)* and genetic (above diagonal) and phenotypic (below diagonal) correlations between test-day FPR and fertility traits DFI, DO, NI and NRR for selected DIMs from a random regression model fitting a second-order orthogonal Legendre polynomials

\begin{tabular}{|c|c|c|c|c|c|c|c|c|c|c|c|c|}
\hline \multirow{3}{*}{ Traits } & & \multicolumn{7}{|c|}{ FPR } & \multirow{2}{*}{ DFI } & \multirow{2}{*}{ DO } & \multirow{2}{*}{$\mathrm{NI}$} & \multirow{2}{*}{ NRR } \\
\hline & DIM & 30 & 60 & 110 & 160 & 210 & 260 & 310 & & & & \\
\hline & 30 & & 0.98 & 0.92 & 0.84 & 0.76 & 0.70 & 0.67 & 0.28 & 0.24 & 0.03 & -0.01 \\
\hline \multirow{6}{*}{ FPR } & 60 & 0.47 & & 0.97 & 0.92 & 0.86 & 0.81 & 0.77 & 0.14 & 0.19 & 0.02 & 0.01 \\
\hline & 110 & 0.35 & 0.37 & & 0.99 & 0.95 & 0.91 & 0.86 & 0.05 & 0.13 & -0.01 & 0.02 \\
\hline & 160 & 0.24 & 0.29 & 0.34 & & 0.99 & 0.96 & 0.92 & -0.01 & 0.09 & -0.10 & 0.04 \\
\hline & 210 & 0.15 & 0.22 & 0.29 & 0.33 & & 0.99 & 0.96 & -0.04 & 0.05 & -0.09 & 0.06 \\
\hline & 260 & 0.12 & 0.17 & 0.25 & 0.29 & 0.32 & & 0.99 & -0.04 & 0.03 & -0.15 & 0.09 \\
\hline & 310 & 0.11 & 0.15 & 0.19 & 0.26 & 0.26 & 0.30 & & -0.01 & 0.03 & -0.21 & 0.12 \\
\hline DFI & & 0.05 & 0.04 & 0.02 & 0.01 & -0.02 & -0.04 & -0.06 & 0.06 & & & \\
\hline DO & & 0.05 & 0.04 & 0.02 & 0.01 & -0.02 & -0.04 & -0.06 & & 0.03 & & \\
\hline NI & & 0.04 & 0.03 & 0.02 & 0.01 & -0.01 & -0.03 & -0.04 & & & 0.01 & \\
\hline NRR & & -0.03 & -0.02 & -0.01 & -0.01 & 0.02 & 0.03 & 0.04 & & & & 0.02 \\
\hline
\end{tabular}

* The heritabilities for test-day FPR are given in Table 2. 